\title{
A history of optogenetics: the development of tools for controlling brain circuits with light
}

\author{
Edward S. Boyden
}

Address: Media Lab, McGovern Institute, Department of Brain and Cognitive Sciences and Department of Biological Engineering, MIT, 77 Massachusetts Avenue, Cambridge, MA 02139, USA

Email: esb@media.mit.edu

Fl000 Biology Reports 20II, 3:II (doi:10.34I0/B3-II)

This is an open-access article distributed under the terms of the Creative Commons Attribution-Non Commercial License (http://creativecommons.org/licenses/by-nc/3.0/legalcode), which permits unrestricted use, distribution, and reproduction in any medium, provided the original work is properly cited. You may not use this work for commercial purposes.

The electronic version of this article is the complete one and can be found at: http://fl000.com/reports/b/3/I I

\begin{abstract}
Understanding how different kinds of neuron in the brain work together to implement sensations, feelings, thoughts, and movements, and how deficits in specific kinds of neuron result in brain diseases, has long been a priority in basic and clinical neuroscience. "Optogenetic" tools are genetically encoded molecules that, when targeted to specific neurons in the brain, enable their activity to be driven or silenced by light. These molecules are microbial opsins, seven-transmembrane proteins adapted from organisms found throughout the world, which react to light by transporting ions across the lipid membranes of cells in which they are genetically expressed. These tools are enabling the causal assessment of the roles that different sets of neurons play within neural circuits, and are accordingly being used to reveal how different sets of neurons contribute to the emergent computational and behavioral functions of the brain. These tools are also being explored as components of prototype neural control prosthetics capable of correcting neural circuit computations that have gone awry in brain disorders. This review gives an account of the birth of optogenetics and discusses the technology and its applications.
\end{abstract}

\section{"How can we invent new tools to understand the brain?"}

For a few years now, I've taught at the Massachusetts Institute of Technology (MIT) a class called "Principles of Neuroengineering," which guides students through the process of creating new neurotechnology innovationsinventions that can solve outstanding scientific questions, or that address unmet clinical needs. This process of neurotechnology invention is difficult, due to the complex properties of the brain: its inaccessibility, heterogeneity, fragility, anatomical richness, and high speed of operation. Thus, for a new neurotechnology invention to work well with the brain, some serendipity is required. Serendipity can be optimized to some degree, however, if one is aware of the complex properties of the brain throughout the entire process of invention, from concept generation all the way to final testing. This awareness, of course, does not insure that this path of innovation will be fast or linear or predictable, but it can support the dynamic process of continually adjusting strategies and reducing risk along the way.

Understanding this dynamic process of innovation might best be accomplished by close examination of case studies, both successful and failed, from the past. Some such case studies in the field of neuroscience have been published, although they focus somewhat more on the science side of things. For example, Andrew Hodgkin wrote a detailed history of his now-classical studies on neural excitability, which were empowered by adapting to neuroscience many tools from the field of electronics [1]. In the preface to his history, he wrote, describing the dynamic path he took, "I think it necessary to give such an account, because I believe that the record of published papers conveys an impression of directness and planning 
which does not at all coincide with the actual sequence of events". To illustrate such a path for a technology in the modern era, I decided it might be useful to write down the history of the development of the tool set known as optogenetics-the set of genetically encoded molecules that, when targeted to specific neurons in the brain, enable their activity to be driven or silenced by light. One great aid to the reconstruction of such case studies in the modern era is the fact that many communications are self-documenting in a form that is easily searched and shared (e.g., emails), and so whenever possible I have tried to use these primary documents to pinpoint when specific events transpired. Of course, the choice to focus on a single trajectory of work also inherently limits the scope of this essay. It is not intended to be a comprehensive review of all the work going on in this field in all labs, but is instead told in a first person voice.

I was fortunate enough to get experience in learning how to control complex systems during my undergraduate days at MIT, where I studied physics and electrical engineering. By the time I graduated, I had helped develop methods for controlling 3D-animated robots and mechanical systems, a prototype nuclear magnetic resonance quantum computer, and an autonomous underwater vehicle, amongst other complex systems. It became clear that learning to control a complex system was important for at least two fundamental reasons. First, this process could help with understanding how the system worked. Second, this process could be useful for fixing the system by enabling its behavior to be steered. I became quite interested in developing strategies for understanding and engineering the brain. As I interviewed for $\mathrm{PhD}$ programs in neuroscience in spring 1999, I asked the scientists I met on each stop the same question: what tools should a physical sciences-trained investigator develop, to help understand the brain?

One fact that emerged from those conversations was that there are many different kinds of neuron in the brain, which possess different morphologies, molecular compositions, and wiring patterns, and which undergo different changes in disease states. New neuron types, and new properties of existing neuron types, are being discovered all the time. This diversity of neuron types stands in contrast to, say, the circuit primitives that make up a computer chip, which fall into a relatively small number of classes, and whose computational properties are understood because they are human-designed. In order to determine how different kinds of neuron in the brain work together to implement brain functions, and to assess the roles that specific sets of neurons play within neural circuits, it would ideally be possible to drive or quiet the activity of defined neurons embedded within an intact neural network. By driving the activity of a specific set of neurons, it would be possible to determine what behaviors, neural computations, or pathologies those neurons were able to cause. And by silencing the activity of a specific set of neurons, it would be possible to determine what brain functions, or pathologies, those neurons were necessary for.

\section{A strategy: controlling the brain with light}

When I started in the $\mathrm{PhD}$ program in neuroscience at Stanford, I hadn't taken a biology course in years. Fortunately, I had incredible freedom to play around, engineering-style, with many different projects in those early days, in part thanks to a fellowship from the Hertz Foundation, and so I learned biology through collaborative projects at the intersection of engineering and biology. In late summer 1999, I set up my home base in Richard Tsien's lab at Stanford, and had time to read about many different topics, ranging from technologies for printing cells in patterns in vitro, to the physiology of synapses, to new kinds of microscopy being developed. Also I was fortunate enough to meet biologists willing to do experiments together: printing substrates on multi-electrode arrays to try to build up neural circuits in vitro with Maitreya Dunham (then a student with David Botstein and Patrick Brown), imaging stem cell differentiation into neurons with Karl Deisseroth (then a Stanford MD-PhD student doing research in the Tsien lab), and learning how to work with rhesus macaques for behavior experiments in Jennifer Raymond's lab. Gong Chen, then a postdoctoral researcher in the Tsien lab, taught me how to culture neurons and to do patch clamp electrophysiology, and gave me free rein to use his Nikon microscope electrophysiology rig in the corner of the Tsien lab, which was equipped with a high-speed switching light source capable of delivering brief pulses of light, for calcium imaging.

For my PhD work, I joined the two labs of Richard Tsien and Jennifer Raymond in spring 2000, to work on the question of how small neural circuits in the cerebellum adapt to control movements as the circumstances of the world change. In parallel, I started thinking about new technologies for controlling the electrical activity of specific neuron types embedded within intact brain circuits. That spring, I discussed this problem during brainstorming sessions, often late at night in the Tsien lab, with Karl Deisseroth. Having trained as an engineer, it was exciting for me to see his clinical perspective on problems of the brain, and we talked extensively about technologies then being explored for repairing neural circuits, from stem cells to transcranial magnetic 
stimulation. We began to systematically think about better ways to control specific neuron types in the brain. Optical uncaging of neurotransmitters with ultraviolet laser pulses was already a powerful method for activating neurons, due to its high speed and spatial precision [2-7], but it had not yet been adapted to a neuron-type specific form $[8,9]$. We started to think about delivering stretch-sensitive ion channels to specific neurons, and then tethering magnetic beads selectively to the channels, so that applying an appropriate magnetic field would result in the bead moving and opening the ion channel, thus activating the target neurons. I did some preliminary calculations that suggested it might be possible to do this. But, using it would seem to require two different molecular reagents: the gene for the stretch-activated channel, as well as magnetic beads that would have to be infused into the brain, perhaps repeatedly, to bind the channels. And, of course, one would also need a magnetic pulse generator capable of the high magnetic field gradients required to move the tiny beads.

By late spring 2000, I had become fascinated by lightdriven ion pumps, naturally occurring seven-transmembrane proteins that contain within them the vitamin A-derived chromophore all-trans-retinal as a light capture molecule. These light-driven ion pumps sounded particularly useful: when illuminated, these proteins, known as opsins, rapidly translocate specific ions across the membranes of the cells in which they are expressed. Opsins had been studied since the 1970s because of their fascinating biophysical propertiesthese molecules undergo fast and rich conformational changes during light-driven ion transport-and also because of the ecological and organismal insights they reveal into how different life forms use light as an energy source or sensory cue. Bacteriorhodopsin, for example, discovered in the early 1970s in the archaeon Halobacterium salinarum [10,11], pumps protons out of cells in response to green light (Figure 1A). In the late 1970s, the related molecule halorhodopsin, an orange light-driven inward chloride pump (Figure 1B), was discovered in the same organism, which lives in high salinity environments where these two ion transport rhodopsins contribute to the bioenergetics of the organism by pumping protons out of, and chloride into, cells in response to light [12-16]. In the early 1980s, the first microbial sensory rhodopsin was discovered: a phototaxis receptor also in the same organism $[17,18]$. Since then, both rhodopsin ion transporters and sensory rhodopsins have been found to be widespread in a diversity of archaea, bacteria, fungi, and algae, where they serve photosynthetic and signaling purposes.
If one were able to find a bacteriorhodopsin or halorhodopsin that worked in neurons, it could be used to pump charged ions across neural membranes in response to light, therefore shutting down the neurons' electrical activity. For this strategy to work, an opsin would have to express, and function, in the neuronal lipid and ionic environment. One reason for optimism was that bacteriorhodopsin had successfully been expressed in eukaryotic cells such as yeast and frog oocytes, and pumped ions in response to light in these heterologous expression systems [19-21]. And in 1999, a paper had come out which showed that, although many halorhodopsins might work best in the high salinity environments in which their host archaea naturally live (i.e., very high chloride concentrations), one halorhodopsin, the halorhodopsin from Natronomonas pharaonis (Halo/NpHR), functioned best, for whatever evolutionary reason, at chloride levels comparable to those in the mammalian brain [22]. I was intrigued by this, and in May 2000 I emailed the opsin pioneer Janos Lanyi, asking for the clone for the $N$. pharaonis halorhodopsin for the purpose of actively controlling neurons with light. Janos kindly asked his collaborator Richard Needleman to send it to me. But the reality of graduate school was setting in: unfortunately I had already departed Stanford for the summer to take a neuroscience class at the Marine Biology Laboratory in Woods Hole. I emailed Richard to ask him to send the clone to Karl. After I returned to Stanford in the fall, I found myself quite busy with learning all the skills I would need for my PhD thesis work on motor control, ranging from how to do mouse surgeries to how to run behavior experiments, and so the opsin project took a backseat for a while.

\section{The channelrhodopsin collaboration}

In 2002, a pioneering paper from the lab of Gero Miesenbock showed that genetic expression of a threegene Drosophila phototransduction cascade in neurons resulted in neurons that could be driven by light [23], and pointed out that the ability to activate specific neurons with light could serve as a tool for finding neural connections, and determining the power of specific neurons to drive activity in neural circuits. The idea for activating genetically targeted neurons with light was clearly in the air. The light-driven currents mediated by this system, however, took many seconds to switch on and off, likely due to the multiprotein nature of the signaling cascade, and this technical issue may have been a factor that limited adoption of the tool. This paper was fresh in my mind when, in fall 2003, Karl emailed me to express interest in talking about the magnetic bead stimulation idea again, as a potential project that we could do together later-when he had his own lab, and when I was done with my PhD and could join his lab as a postdoctoral 
Figure I. Adaptation of microbial opsins from nature for the optical control of neural activity

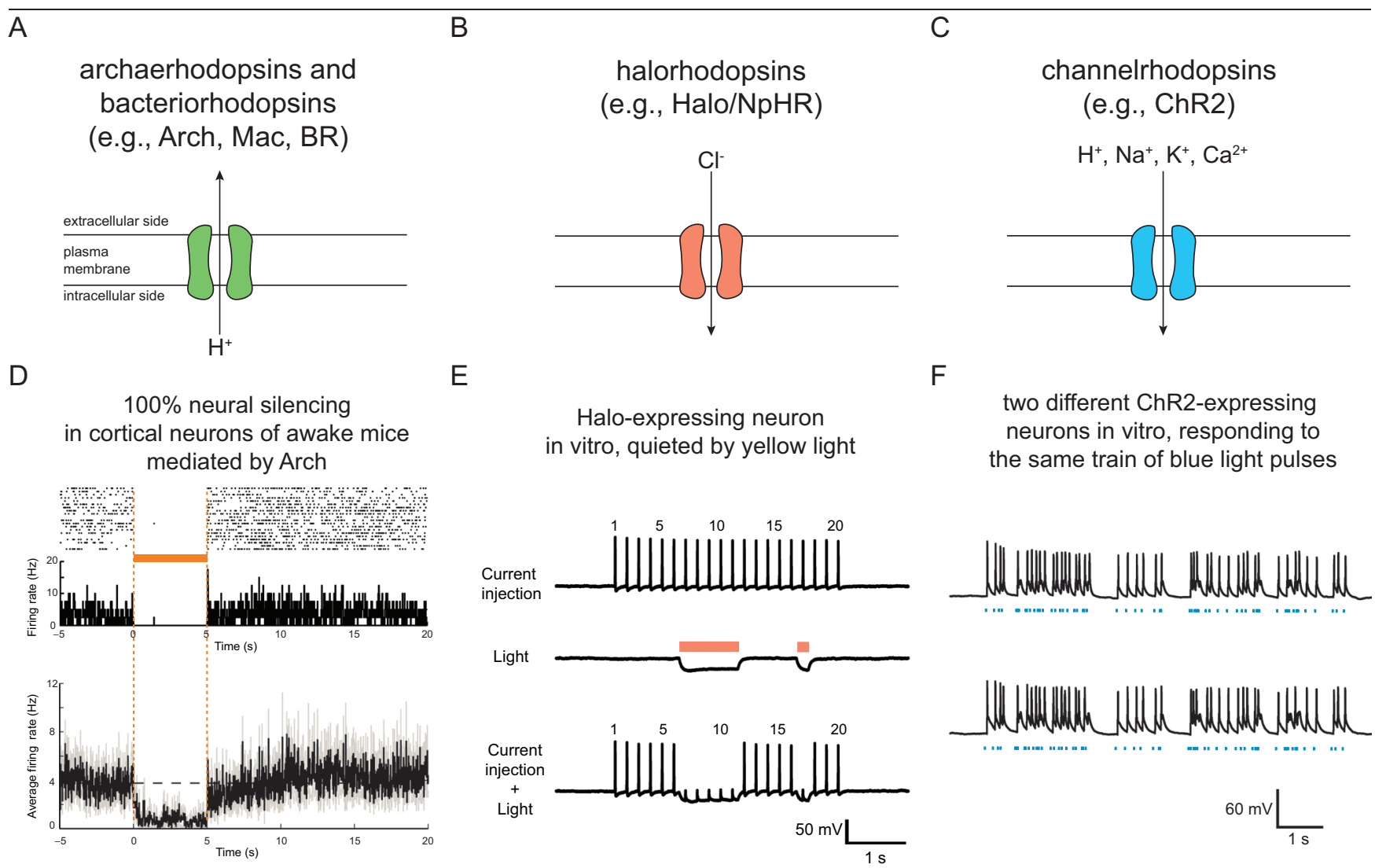

(A-C) Diagrams depicting the physiological responses of (A) archaerhodopsins and bacteriorhodopsins (light-driven outward proton pumps),

(B) halorhodopsins (light-driven inward chloride pumps), and (C) channelrhodopsins (light-gated inward nonspecific cation channels), when expressed in the plasma membranes of neurons and exposed to light. (D) Demonstration of use of Halobacterium sodomense archaerhodopsin-3 (Arch) to mediate light-driven neural silencing in cortical pyramidal neurons of awake mice. Top: Neural activity in a representative neuron before, during, and after 5 seconds of yellow light illumination, shown as a spike raster plot (upper panel), and as a histogram of instantaneous firing rate averaged across trials (lower panel; bin size, $20 \mathrm{~ms}$ ). Bottom: Population average of instantaneous firing rate before, during, and after yellow light illumination (black line, mean; gray lines, mean \pm SE; $n=13$ units). Adapted from [36]. (E) Demonstration of use of Natronomonas pharaonis halorhodopsin (Halo/NpHR) to mediate light-driven spike quieting, demonstrated for a representative hippocampal neuron in vitro. Top: (“Current injection"), neuronal firing of 20 spikes at $5 \mathrm{~Hz}$, induced by pulsed somatic current injection ( 300 pA, 4 ms). Middle: ("Light"), membrane hyperpolarization induced by two periods of yellow light, timed so as to be capable of blocking spikes 7-II and spike 17 out of the train of 20 spikes. Bottom: ("Current injection + Light"), yellow light drives Halo to block neuron spiking (note absence of spikes 7-II and of spike 17), while leaving intact the spikes elicited during periods of darkness. Adapted from [34]. (F) Demonstration of use of Chlamydomonas reinhardtii channelrhodopsin-2 (ChR2) to mediate light-driven spiking in two different hippocampal neurons, in response to the same train of blue light pulses (with timings selected from a Poisson distribution with mean interval $\lambda=100 \mathrm{~ms}$ ). Adapted from [26]. BR, bacteriorhodopsin.

researcher-given our shared interests in controlling brain computations. Karl was then a postdoctoral researcher in Robert Malenka's lab. I was then about halfway through my $\mathrm{PhD}$ on motor learning in the labs of Jennifer Raymond and Richard Tsien; I am very thankful for their mentorship and for crafting an environment where people felt free to tackle big problems.

Between October 2003 and February 2004, Karl and I read through published papers where people had perturbed cell physiology with magnetic beads, began to figure out how to connect the beads to channels, and did new rounds of calculations on the magnetic beads. I also read a just-published paper by Georg Nagel, Ernst Bamberg, Peter Hegemann, and colleagues announcing the discovery that the opsin that drives phototaxis in the green alga Chlamydomonas reinhardtii [24] was a lightgated cation channel (Figure 1C) that, when illuminated, lets positively charged ions (such as $\mathrm{H}+$ and $\mathrm{Na}+$ ) pass into cells in which it is heterologously expressed [25]. Nagel et al. accordingly named this molecule channelrhodopsin-2, and demonstrated in that paper that it could be used to depolarize cells such as oocytes or HEK (Human Embyonic Kidney) cells in response to light, 
commenting presciently that channelrhodopsin-2 "should become a useful tool to manipulate intracellular $\mathrm{Ca}^{2+}$ concentration or membrane potential, especially in mammalian cells." Using a light-activated channel would require, for in vivo use, an implanted optical fiber to be inserted into the brain, which at first glance might seem more invasive than a noninvasive magnetic field. But upon reflection, even the magnetic bead idea would be invasive: the magnetic beads would have to be injected into the brain, perhaps repeatedly as the beads were eliminated by the body. Furthermore, it seemed that, given the technology development curves that were bringing microscopy increasingly into systems neuroscience (e.g., the increasing popularity of two-photon microscopy), a light-driven method might find rapid adoption by the neuroscience community. In February 2004, I emailed Karl proposing that we contact Georg to see if they had constructs they were willing to distribute. Karl emailed Georg in March, obtaining the clone for channelrhodopsin-2 from Georg on a collaborative basis, and then put the gene into a neural expression vector. Georg had made several further important advances by then: he had shown that channelrhodopsin-2 formed stable fusion proteins with fluorescent proteins such as YFP (yellow fluorescent protein), useful for monitoring channelrhodopsin-2 expression in heterologous systems, and had found a channelrhodopsin-2 mutant less prone to inactivation than the wild-typethe H134R mutant-which he sent to us as well. Also, Georg commented that little or no all-trans-retinal needed to be supplemented to channelrhodopsin-2expressing cells being recorded in vitro-perhaps the chemical chromophore of channelrhodopsin-2, all-transretinal, was already present in cells or cell culture media at levels high enough to support opsin function.

Finally, we were getting the ball rolling on neuron-type targetable neural control. Karl and I brainstormed about all sorts of things we could do: two-photon activation of different neurons, obtaining neuron type-specific promoters with which to target channelrhodopsin-2 expression to different cells, mutating channelrhodopsin-2 to make multiple color variants, and so forth. Of course, going after a tool based on a natural molecule such as channelrhodopsin-2 presented risks; many things could go wrong. Channelrhodopsin-2 might not express well in neurons, requiring further, potentially painstaking, molecular optimization to become compatible with the neuronal milieu. Or, channelrhodopsin-2 in neurons might require its retinal chromophore cofactor to be externally supplied, making channelrhodopsin-2utilizing experiments complicated and dependent on chemical supplementation. Or, perhaps channelrhodop$\sin -2$ would not be able to mediate currents of sufficient magnitude to result in neural spikes or action potentials. Or, since the paper describing the discovery of channelrhodopsin-2 was already out, we might be racing other labs to see if it worked in neurons.

Karl worked to optimize the transfection conditions to get channelrhodopsin-2 expression in cultured hippocampal neurons, and found that indeed neurons could tolerate channelrhodopsin-2 expression, and that the expression was membrane localized. This was good news: many past attempts to express natural opsins in heterologous expression systems had not panned out, perhaps because opsins that evolved in one lipid and ionic milieu might not be optimal for another. I was eager to look at the physiology of channelrhodopsin-2expressing neurons. Throughout July, working in the offhours when I was not working on my thesis projects, I debugged the optical filters and learned to program the fast-switching optics on the very same rig in the Tsien lab on which Gong Chen had taught me to patch clamp, years earlier. I owe Richard Tsien a debt of gratitude for providing an environment in which new ideas could be pursued, and I regret that we did not acknowledge in our first paper on optogenetics that many of the key experiments had been done in his lab.

Late at night, around 1 a.m. on August 4, 2004, I went into the Tsien lab, put a dish of cultured neurons expressing channelrhodopsin-2-YFP into the microscope, patch clamped a glowing neuron, and triggered the program that I had written to pulse blue light at the neurons. To my amazement, the very first neuron I patched (Figure 2) fired precise action potentials in response to blue light. That night I collected data that demonstrated all the core principles of the Nature Neuroscience paper that we published in 2005, announcing that channelrhodopsin-2 could be used to depolarize neurons [26]. In that first night of experimentation in 2004, I found that channelrhodopsin-2 was safely expressed, and physiologically functional, when expressed in neurons. Despite the small single channel conductance of channelrhodopsin-2, the protein was well-tolerated enough by neurons to be expressed at high enough levels to mediate strong neural depolarizations. Indeed, even with brief pulses of blue light, the magnitude of expressed channelrhodopsin- 2 photocurrents was large enough to mediate single action potentials in neurons, thus enabling detailed and temporally precise driving of precision spike trains (Figure $1 \mathrm{~F}$ ). Activating a neuron expressing channelrhodopsin-2 repeatedly with light, over periods of half an hour or so, did not seem to cause rundown of channelrhodopsin-2 performance, or impair the neuron's physiology, which boded well for its utility in a 
Figure 2. Early data showing that channelrhodopsin-2 could mediate light-driven spiking in neurons

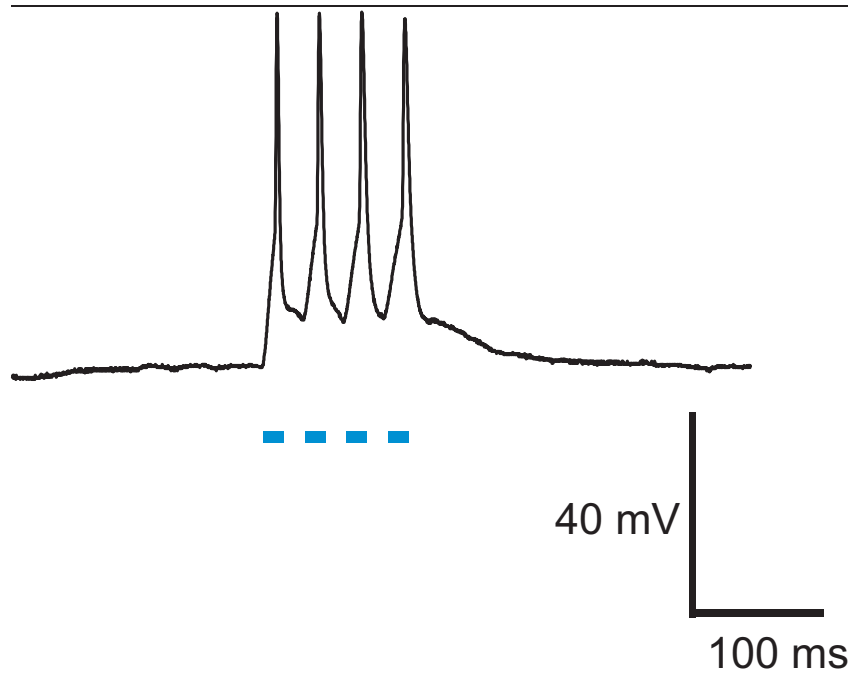

Raw voltage trace recorded from a current-clamped neuron in vitro, expressing channelrhodopsin- 2 and exhibiting light-activated spikes, here driven by four 15 ms-duration blue light pulses. The data here shown were acquired from the first channelrhodopsin-2-expressing neuron recorded in the study that culminated in [26].

diversity of neuroscience experiments. And, by using pulse trains of blue light, channelrhodopsin-2 could mediate action potentials at tens of $\mathrm{Hz}$, although the channel kinetics prevented significantly faster action potential trains from being driven. Finally, channelrhodopsin-2 inactivated upon extended illumination, but recovered spontaneously, at a rate fast enough to support useful neuroscience experiments. Serendipity had struck-the molecule was good enough in its wildtype form to be used in neurons right away.

After a long night of characterizing the functions of channelrhodopsin-2 in neurons, I emailed Karl, "Tired, but excited." He emailed back, "This is great!!!!!".

\section{Transitions and optical neural silencers}

In January 2005, Karl transitioned from being a postdoctoral researcher to being an assistant professor at Stanford. Feng Zhang, then a first year graduate student in chemistry (and now an assistant professor at MIT and at the Broad Institute), had joined Karl's lab, where he cloned channelrhodopsin-2 into a lentiviral vector, and produced lentivirus that greatly increased the robustness of channelrhodopsin-2 expression over that mediated by the transfection methods that Karl and I had used when we launched the project. At the time, I was still a PhD student with Richard Tsien and Jennifer Raymond, and I continued to perform channelrhodopsin-2 experiments in the Tsien lab (indeed, about half the channelrhodopsin-2 experiments in our 2005 Nature Neuroscience paper [26] were done in the Tsien lab; I started doing experiments in Karl's lab in late March 2005). We confirmed that background levels of all-trans-retinal were sufficient to support channelrhodopsin-2 function in neurons, and we carried out experiments to flesh out all the figures of our paper. Guoping Feng, then leading a lab at Duke University (and now a professor at MIT), began to make the first transgenic mice expressing channelrhodopsin-2 in neurons around that time as well (published in $[27,28]$ ).

We submitted the paper describing the use of channelrhodopsin-2 to Science on April 19, 2005, where it was rejected on the grounds that we hadn't made any scientific discoveries beyond finding that channelrhodopsin-2 functioned well in neurons. On May 5, we resubmitted it to Nature, where it was then relayed to Nature Neuroscience, and after one round of revision the paper was accepted there, appearing online in August 2005 [26]. The term "optogenetics" was coined during this period, and first used in [29] to refer to the use of light to image genetically-expressed reporters of neural function as well as to perturb genetically targeted neurons (although some scientists now use the term chiefly to refer to tools for neural manipulation).

Several other groups rapidly published papers demonstrating the use of channelrhodopsin-2 in neurons in the months following, including use in intact mammalian brain circuits by the Yawo lab ([30], which appeared online in November 2005), in the chick spinal cord by the Herlitze and Landmesser labs ([31], which also appeared online in November 2005), in the behaving worm by the Nagel and Gottschalk labs ([32], which appeared online in December 2005), and in the retina by the Pan lab ([33], which appeared online in April 2006). The idea had most definitely been in the air, with many groups chasing the use of channelrhodopsin in neurons. These papers showed, amongst many other pioneering results, that no chemicals were needed to supplement channelrhodopsin2 function in the living mammalian brain, verifying in vivo what we had found in cultured neurons before-that no retinal cofactor needed to be externally supplied [26]. The Herlitze and Landmesser paper also remarkably demonstrated the use of mammalian rhodopsin for light-activated neural silencing, reporting that mammalian rhodopsin could drive the opening of G-protein-coupled potassium channels via the G-protein $G_{i}[31]$.

I started getting positive feedback on channelrhodopsin-2 right away, and so almost immediately after I finished my $\mathrm{PhD}$ thesis on motor learning in October 2005, two 
months after the channelrhodopsin-2 paper came out, I began the faculty job search process. At the same time, I started a position as a postdoctoral researcher with Karl and with Mark Schnitzer at Stanford. The job search process ended up consuming much of my time, and being on the road, I began doing bioengineering invention consulting in order to help me learn about and explore new technology areas that could be brought to bear on neuroscience. I accepted a faculty job offer from the MIT Media Lab in September 2006, and began the process of setting up a neuroengineering research group there.

Around that time, I began a collaboration with Xue Han, my then-girlfriend (and then a postdoctoral researcher in the lab of Richard Tsien), to revisit the original idea of using the $N$. pharaonis halorhodopsin to mediate optical neural silencing. Xue was in the process of moving out to Boston, where she eventually became a postdoctoral researcher working between my group and Robert Desimone's group. Given that back in 2000, Karl and I had planned to pursue this jointly, there was now the potential for competition now that we were working separately. Xue and I ordered the gene to be synthesized in codon-optimized form by a DNA synthesis company, and, using the same rig in Richard Tsien's lab that had supported the channelrhodopsin paper, Xue acquired data for a paper showing that this halorhodopsin indeed could silence neural activity (Figure 1E). We submitted our paper to PLoS ONE, where it came out in March 2007 [34]. Meanwhile, Karl's group, working in parallel, came out with a paper in Nature a few weeks after ours, showing independently that this halorhodopsin could support light-driven silencing of neurons, and also including an impressive demonstration that it could be used to manipulate behavior in Caenorhabditis elegans [35]. Later, both of our groups teamed up to file a joint patent on the use of this halorhodopsin to silence neural activity. As a testament to the unanticipated side effects of following innovation where it leads you, Xue and I got married in 2009 (and she is now an assistant professor at Boston University).

While halorhodopsin neural silencing was valuable as a proof of concept, there were performance limitations, including the low magnitude of the current, and also the fact that halorhodopsins, when illuminated for periods of tens of seconds, tended to get stuck in an inactivated state, with a slow recovery period (taking tens of minutes) [36-38]. I continued to order genes to be synthesized that corresponded to different opsins or putative opsins, continuing to survey genomic diversity for better silencing opsins. The inexpensiveness of total gene synthesis meant that it was possible to rapidly obtain genes codon-optimized for eukaryotic or mammalian expression, and then to screen them for new and interesting light-drivable neural functions. Brian Chow (who recently accepted an assistant professor position at the University of Pennsylvania), an expert on genomics and synthetic biology, joined my lab at MIT as a postdoctoral researcher, and began collaborating with Xue; together, they found a new class of neural silencer, the archaerhodopsin class (Figure 1A), which was not only capable of high amplitude neural silencing - the first that could support complete 100\% shutdown of neurons in the awake behaving animal (Figure 1D) - but also was capable of rapid recovery after having been illuminated for extended durations; we published this finding in Nature in January 2010 [36]. The class of archaerhodopsins possesses several key properties that make these opsins particularly highperformance light-driven neural silencers, including fast kinetics, which helps these opsins mediate high currents. Interestingly, the archaerhodopsins are light-driven outward proton pumps, similar to bacteriorhodopsin-they hyperpolarize neurons by pumping protons out of the cells. However, the resultant $\mathrm{pH}$ changes are as small as those produced by channelrhodopsins (which have proton conductances a million times greater than their sodium conductances) [36,39], and are well within the safe range of neuronal operation. Intriguingly, we discovered that the H. salinarum bacteriorhodopsin, the first opsin characterized in the early 1970s, was able to mediate decent optical neural silencing [36], suggesting that perhaps opsins could have been applied to neuroscience decades ago.

\section{Applications: neuroscience and therapy}

Usage of optogenetic tools has exploded, with new papers arising frequently that use opsins to mediate either the activation or silencing of specific neuron classes with light in order to see how neurons contribute to behavior in organisms including C. elegans, Drosophila, zebrafish, mouse, rat, and nonhuman primate. Conventional mercury and xenon lamps, light-emitting diodes, shutters, scanning lasers, femtosecond lasers, and other common microscopy equipment suffice for in vitro use. In vivo mammalian use of these reagents has been greatly facilitated by the availability of inexpensive lasers with optical fiber outputs; the free end of the optical fiber is simply inserted into the brain of the live animal when needed [40,41], or coupled at the time of experimentation to a chronically-implanted optical fiber. In just the first three years after the first paper on channelrhodopsin-2 in neurons, these tools were used in vivo to determine how specific kinds of neuron modulate brain functions such as learning [42], wakening [43], somatosensation [44-46], vision $[47,48]$, breathing [49], and movement $[40,50,51]$. These tools were also used to activate defined neural 
pathways, and to perform circuit mapping experiments, in mammalian brain slices [28,52-56] and in vivo [27]. Since then, topics ranging from Parkinson's disease to fear to cortical dynamics to pain have been explored using optogenetics, as the tools become ever more widespread.

In 2009 my group published, in collaboration with the labs of Robert Desimone and Ann Graybiel at MIT, the first use of channelrhodopsin-2 in the nonhuman primate brain, showing that it could safely and effectively mediate neuron type-specific activation in the rhesus macaque, without provoking neuron death or functional immune reactions [57]. This paper opened up the possibility of translation of optical neural stimulation into the clinic as a potential treatment modality, although clearly much more work is required to understand this potential application of optogenetics. Recently we have found that Arch (archaerhodopsin-3 from Halobacterium sodomense), and more light-sensitive variants such as ArchT, also work well in the nonhuman primate brain, mediating near- $100 \%$ neural silencing of cortical neurons in the awake primate in response to light [58]; the ability to transiently silence specific neurons with light might open up fundamentally new kinds of clinical possibility in the treatment of disorders where specific neurons are overexcitable.

For mammalian systems, viruses bearing genes encoding for opsins have proven popular in experimental use, due to their ease of creation and use; these viruses achieve their specificity either by being taken up by specific neurons and not others, or by containing regulatory promoters that constrain opsin expression to specific kinds of neuron $[26,30,33]$. One popular hybrid strategy is to obtain one of the burgeoning number of mice that express Cre recombinase in specific neuron types, and then to inject a virus that contains a Cre-activated genetic cassette encoding for the opsin, so that only in the Cre recombinase-expressing neurons will the opsin be produced $[55,59,60]$. An increasing number of transgenic mice are also starting to emerge, in which an opsin is expressed in a given neuron type through transgenic methodologies $[27,61,62]$.

My group at MIT has distributed these tools to approximately 400 research groups worldwide, as of early 2011, and Karl's group has also distributed the tools to many hundreds of labs as well. An essential aspect of this work is the desire to distribute these tools freely and openly, even pre-publication. Furthermore, to facilitate the teaching of people in how to use these tools, our lab regularly posts white papers on our web page [63] with details on reagents and optical hardware (a complete optogenetics setup costs as little as a few thousand dollars for all required hardware and consumables), and we have also partnered with nonprofit organizations such as Addgene and the University of North Carolina Gene Therapy Core to distribute DNA and viruses (the latter, prompted by a suggestion from Karel Svoboda), respectively. We regularly host visitors to see how we do experiments, as the community building aspect has been a central part of optogenetics from the beginning.

\section{Beyond luck: systematic discovery and engineering of optogenetic tools}

The original optogenetic tools were identified in part through serendipity, guided by a multidisciplinary convergence, and a neuroscience-driven knowledge of what might make a good tool. It is clear, looking back, that enormous amounts of luck were involved in making the rapid identification of the first three classes of optogenetic tool possible. As a strategy, the power of inexpensive gene synthesis, coupled to rapid direct electrophysiological assessment in heterologous expression systems, has proven valuable because it allows one to rapidly screen through codon-optimized genes in a mammalian neuronal context. Now this process of luck optimization has become a science: new optogenetic tools are emerging through systematic means; for example, the screening through genomes for new lightactivated proteins, and the systematic mutagenesis of existing opsins, as principles of ecological discovery and molecular engineering emerge. More powerful molecules, more light-sensitive molecules, and molecules with novel spectral characteristics, are opening up the ability to do fundamentally new kinds of experiment, as well as the ability to do more precise or powerful experiments.

As just one example from my lab, Brian Chow and Xue Han discovered that although the original halorhodopsin is sensitive to light in the yellow-to-red-range, the opsin from the fungus Leptosphaeria maculans, Mac, can mediate neural silencing in response to blue light [36], so that two kinds of neurons, one expressing the $N$. pharaonis halorhodopsin and one expressing Mac, can be differentially silenced by red and blue light respectively (Figure 3 ). However, there is still significant crosstalk due to overlap in the activation spectra between the pairs of opsins (i.e., Mac is slightly driven by red light and halorhodopsin is slightly driven by blue light) described above. Similarly, channelrhodopsins that are red-shifted in activation spectrum relative to channelrhodopsin-2 have been identified [64,65]. Ideally reagents could be devised that would be even further spectrally separated than the existing tools. In addition, opsins that are red- or infrared-light drivable would be desirable, because such light can penetrate deeper into 
Figure 3. Genomic diversity of opsins enables multicolor silencing of different neural populations

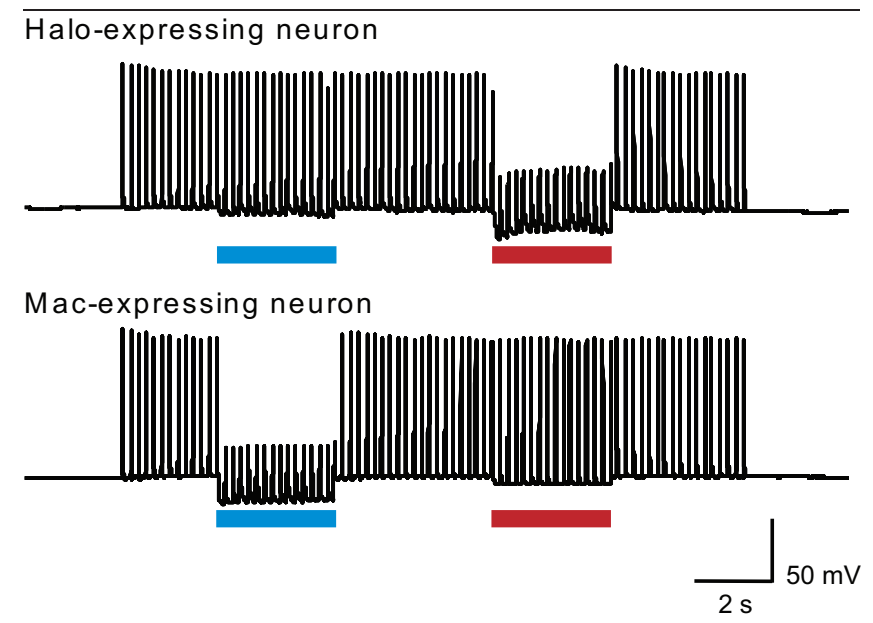

Neurons expressing the Natronomonas pharaonis halorhodopsin (Halo) (top) were selectively quieted by red light and not by blue light, whereas neurons expressing the Leptosphaeria maculans opsin (Mac) were selectively quieted by blue light and not by red light (bottom). Data were acquired from opsinexpressing neurons current-clamped in vitro, and spikes were induced by pulsed somatic current injection, as in Figure IE. Adapted from [36].

the brain, enhancing the usefulness of the tools both in a scientific sense and perhaps in a translational or clinical sense. A lot of new capabilities are emerging at the intersection of microbiology and plant biology, gene and transcriptome sequencing, and bioengineering and neuroscience; for example, we have entered into collaborations like the OneKP project, headed by Gane Wong at the University of Alberta, to mine vast new genomic resources for light-drivable molecules.

A second area of activity in the optogenetic tool development space has been to alter existing opsins by mutation, chimeragenesis, or other molecular alteration strategies, to tune the performance of the opsin towards different capabilities. For decades, scientists have mutated targeted residues in opsins, and observed changes in kinetics, spectra, and other properties [36,66-73]. Recently, a number of groups have mutated key amino acids within channelrhodopsin-2, creating versions that stay open for long periods of time after a brief pulse of light $[74,75]$, or that close quickly after the light pulse ends $[39,76]$. Other versions have been created that do not inactivate as quickly $[32,39,77]$, or that are more light sensitive or higher amplitude when expressed in neurons [78]. Furthermore, attempts have been made to enable better expression of halorhodopsin (which forms aggregates when expressed at high levels) in neurons by adding sequences from potassium channels to improve their trafficking [79-82]. The ability to use high-throughput screening and directed evolution to optimize opsins, which revolutionized the creation of fluorescent proteins and many other bioengineering tools, may greatly advance the ability to create opsins with desired properties.

In some ways, the original serendipity, associated with synthesizing a concept then rapidly giving it a try to see what might work out in the context of the nervous system, has now given way to the systematized luck of bioengineering, with its machines and algorithms designed to optimize the chances of finding something new. Perhaps, of course, even as this systematized luck accelerates, we will stumble upon new and entirely unexpected innovations that work well amidst the complexity of the brain-and perhaps that will be the seed for a new bit of serendipity, beginning the cycle again.

\section{Abbreviations}

Arch, archaerhodopsin-3 from Halobacterium sodomense; Mac, opsin from Leptosphaeria maculans; MIT, Massachusetts Institute of Technology; YFP, yellow fluorescent protein.

\section{Competing interests}

ESB has numerous pending patents in the field, and is also co-founder of Eos Neuroscience.

\section{Acknowledgements}

ESB acknowledges funding by the NIH Director's New Innovator Award (DP2OD002002) as well as NIH Grants 1R01DA029639, 1RC1MH088182, 1RC2DE020919, 1R01NS067199 and 1R43NS070453; the NSF CAREER award as well as NSF Grants EFRI 0835878, DMS 0848804, and DMS 1042134; Benesse Foundation, Jerry and Marge Burnett, Department of Defense CDMRP PTSD Program, Google, Harvard/MIT Joint Grants Program in Basic Neuroscience, Human Frontiers Science Program, MIT Alumni Class Funds, MIT Intelligence Initiative, MIT McGovern Institute and the McGovern Institute Neurotechnology Award Program, MIT Media Lab, MIT Mind-Machine Project, MIT Neurotechnology Fund, NARSAD, Paul Allen Family Foundation, Alfred P. Sloan Foundation, SFN Research Award for Innovation in Neuroscience, and the Wallace H. Coulter Foundation. Thanks also to Charles Jennings, Robert Desimone, Jennifer Raymond, Brian Chow, Robert Horvitz, John Spudich, Gyorgy Buzsaki, Lowell Wood, Sam Wang, Philip Low, Chris Moore, Scott Sternson, Joost Bonsen, Meyer Jackson, Ed Callaway, Karel Svoboda, Uma Karmarkar, Eric Leuthardt, Terry Sejnowski, Xue Han, Jeannie Stamberger, and Nancy Kopell for comments on this paper. 


\section{References}

I. Hodgkin AL: Chance and design in electrophysiology: an informal account of certain experiments on nerve carried out between 1934 and 1952. J Physiol 1976, 263:I-2I.

2. O'Neill SC, Mill JG, Eisner DA: Local activation of contraction in isolated rat ventricular myocytes. Am J Physiol 1990, 258: CII65-8.

3. Hess GP, Niu L, Wieboldt R: Determination of the chemical mechanism of neurotransmitter receptor-mediated reactions by rapid chemical kinetic methods. Ann N Y Acad Sci 1995, 757:23-39.

4. Adams SR, Tsien RY: Controlling cell chemistry with caged compounds. Annu Rev Physiol 1993, 55:755-84.

5. Wang SS, Augustine GJ: Confocal imaging and local photolysis of caged compounds: dual probes of synaptic function. Neuron 1995, 15:755-60.

6. Callaway EM, Katz LC: Photostimulation using caged glutamate reveals functional circuitry in living brain slices. Proc Natl Acad Sci U S A 1993, 90:766I-5.

7. Parker I, Yao Y: Regenerative release of calcium from functionally discrete subcellular stores by inositol trisphosphate. Proc Biol Sci 199I, 246:269-74.

8. Zemelman BV, Nesnas N, Lee GA, Miesenbock G: Photochemical gating of heterologous ion channels: remote control over genetically designated populations of neurons. Proc Natl Acad Sci U S A 2003, 100:1352-7.

9. Lima SQ, Miesenbock G: Remote control of behavior through genetically targeted photostimulation of neurons. Cell 2005, |21:141-52.

FI000 Factor 13

Evaluated by Liqun Luo 09 May 2005, Yadin Dudai 17 May 2005

10. Oesterhelt D, Stoeckenius W: Functions of a new photoreceptor membrane. Proc Natl Acad Sci U S A 1973, 70:2853-7.

II. Oesterhelt D, Stoeckenius W: Rhodopsin-like protein from the purple membrane of Halobacterium halobium. Nat New Biol 197I, 233:149-52.

12. Matsuno-Yagi A, Mukohata Y: Two possible roles of bacteriorhodopsin; a comparative study of strains of Halobacterium halobium differing in pigmentation. Biochem Biophys Res Commun 1977, 78:237-43.

13. Mukohata $Y$, Kaji $Y$ : Light-induced membrane-potential increase, ATP synthesis, and proton uptake in Halobacterium halobium, $R I m R$ catalyzed by halorhodopsin: Effects of $\mathbf{N}, \mathbf{N}$ '-dicyclohexylcarbodiimide, triphenyltin chloride, and 3,5-di-tert-butyl-4-hydroxybenzylidenemalononitrile (SF6847). Arch Biochem Biophys 198I, 206:72-6.

14. Schobert B, Lanyi JK: Halorhodopsin is a light-driven chloride pump. J Biol Chem 1982, 257:10306-13.

15. Lanyi JK, Weber HJ: Spectrophotometric identification of the pigment associated with light-driven primary sodium translocation in Halobacterium halobium. J Biol Chem 1980, 255:243-50.

16. Matsuno-Yagi A, Mukohata Y: ATP synthesis linked to lightdependent proton uptake in a rad mutant strain of Halobacterium lacking bacteriorhodopsin. Arch Biochem Biophys 1980, 199:297-303.

17. Spudich EN, Spudich JL: Control of transmembrane ion fluxes to select halorhodopsin-deficient and other energy-transduction mutants of Halobacterium halobium. Proc Natl Acad Sci U S A 1982, 79:4308-12.

18. Bogomolni RA, Spudich JL: Identification of a third rhodopsinlike pigment in phototactic Halobacterium halobium. Proc Natl Acad Sci U S A 1982, 79:6250-4.

19. Nagel G, Mockel B, Buldt G, Bamberg E: Functional expression of bacteriorhodopsin in oocytes allows direct measurement of voltage dependence of light induced $\mathbf{H +}$ pumping. FEBS Lett 1995, 377:263-6.
20. Hildebrandt V, Fendler K, Heberle J, Hoffmann A, Bamberg E, Buldt G: Bacteriorhodopsin expressed in Schizosaccharomyces pombe pumps protons through the plasma membrane. Proc Natl Acad Sci U S A 1993, 90:3578-82.

21. Hildebrandt V, Ramezani-Rad M, Swida U, Wrede P, Grzesiek S, Primke M, Buldt G: Genetic transfer of the pigment bacteriorhodopsin into the eukaryote Schizosaccharomyces pombe. FEBS Lett 1989, 243:137-40.

22. Okuno D, Asaumi M, Muneyuki E: Chloride concentration dependency of the electrogenic activity of halorhodopsin. Biochemistry 1999, 38:5422-29.

23. Zemelman BV, Lee GA, Ng M, Miesenbock G: Selective photostimulation of genetically chARGed neurons. Neuron 2002, 33:I5-22.

FI000 Factor 10

Evaluated by Roger Hardie 04 Feb 2002

24. Sineshchekov OA, Jung KH, Spudich JL: Two rhodopsins mediate phototaxis to low- and high-intensity light in Chlamydomonas reinhardtii. Proc Natl Acad Sci U S A 2002, 99:8689-94.

25. Nagel G, Szellas T, Huhn W, Kateriya S, Adeishvili N, Berthold P, Ollig D, Hegemann P, Bamberg E: Channelrhodopsin-2, a directly light-gated cation-selective membrane channel. Proc Natl Acad Sci U S A 2003, 100:13940-5.

26. Boyden ES, Zhang F, Bamberg E, Nagel G, Deisseroth K: Millisecondtimescale, genetically targeted optical control of neural activity. Nat Neurosci 2005, 8: I263-8.

FI000 Factor 15

Evaluated by John Lisman 07 Sep 2005, Michael Ehlers 06 Oct 2005, Yoshimi Takai I6 Dec 2005, Matteo Carandini 3 I Jul 2006

27. Arenkiel BR, Peca J, Davison IG, Feliciano C, Deisseroth K, Augustine G], Ehlers MD, Feng G: In vivo light-induced activation of neural circuitry in transgenic mice expressing channelrhodopsin-2. Neuron 2007, 54:205-18.

FI000 Factor 7

Evaluated by Yvette Taché 20 Apr 2007, Shai Shaham 24 Apr 2007

28. Wang H, Peca J, Matsuzaki M, Matsuzaki K, Noguchi J, Qiu L, Wang D, Zhang F, Boyden E, Deisseroth K, Kasai H, Hall WC, Feng G, Augustine GJ: High-speed mapping of synaptic connectivity using photostimulation in Channelrhodopsin-2 transgenic mice. Proc Natl Acad Sci U S A 2007, 104:8I43-8.

29. Deisseroth K, Feng G, Majewska AK, Miesenbock G, Ting A, Schnitzer MJ: Next-generation optical technologies for illuminating genetically targeted brain circuits. J Neurosci 2006, 26: 10380-6.

30. Ishizuka T, Kakuda M, Araki R, Yawo H: Kinetic evaluation of photosensitivity in genetically engineered neurons expressing green algae light-gated channels. Neurosci Res 2006, 54:85-94.

3I. Li X, Gutierrez DV, Hanson MG, Han J, Mark MD, Chiel H, Hegemann P, Landmesser LT, Herlitze S: Fast noninvasive activation and inhibition of neural and network activity by vertebrate rhodopsin and green algae channelrhodopsin. Proc Natl Acad Sci U S A 2005, 102: 17816-21.

32. Nagel G, Brauner M, Liewald JF, Adeishvili N, Bamberg E, Gottschalk A: Light activation of channelrhodopsin-2 in excitable cells of Caenorhabditis elegans triggers rapid behavioral responses. Curr Biol 2005, 15:2279-84.

33. Bi A, Cui J, Ma YP, Olshevskaya E, Pu M, Dizhoor AM, Pan ZH: Ectopic expression of a microbial-type rhodopsin restores visual responses in mice with photoreceptor degeneration. Neuron 2006, 50:23-33.

FI000 Factor 8

Evaluated by Gordon Fain 19 Apr 2006

34. Han X, Boyden ES: Multiple-color optical activation, silencing, and desynchronization of neural activity, with single-spike temporal resolution. PLoS ONE 2007, 2:e299.

FI000 Factor 8

Evaluated by Ellen A Lumpkin II Jun 2007 
35. Zhang F, Wang LP, Brauner M, Liewald JF, Kay K, Watzke N, Wood PG, Bamberg E, Nagel G, Gottschalk A, Deisseroth K: Multimodal fast optical interrogation of neural circuitry. Nature 2007, 446:633-9.

FI000 Factor 26

Evaluated by Tullio Pozzan 10 Apr 2007, Edvard I Moser II Apr 2007, Eileen Lafer 16 Apr 2007, David P Wolfer 19 Apr 2007, Shai Shaham 24 Apr 2007, Joel Elmquist 09 May 2007, Ellen A Lumpkin II Jun 2007, Michael Kiebler 24 Jul 2007

36. Chow BY, Han X, Dobry AS, Qian X, Chuong AS, Li M, Henninger MA, Belfort GM, Lin Y, Monahan PE, Boyden ES: Highperformance genetically targetable optical neural silencing by light-driven proton pumps. Nature 2010, 463:98-102.

FI000 Factor 10

Evaluated by Luis de Lecea 19 Jan 2010, Jan-Marino Ramirez 06 May 2010

37. Bamberg E, Tittor J, Oesterhelt D: Light-driven proton or chloride pumping by halorhodopsin. Proc Natl Acad Sci U S A 1993, 90:639-43.

38. Hegemann P, Oesterbelt D, Steiner M: The photocycle of the chloride pump halorhodopsin. I: Azide-catalyzed deprotonation of the chromophore is a side reaction of photocycle intermediates inactivating the pump. EMBO J 1985, 4:2347-50.

39. Lin JY, Lin MZ, Steinbach P, Tsien RY: Characterization of engineered channelrhodopsin variants with improved properties and kinetics. Biophys J 2009, 96:|803-I4.

40. Aravanis AM, Wang LP, Zhang F, Meltzer LA, Mogri MZ, Schneider MB, Deisseroth K: An optical neural interface: in vivo control of rodent motor cortex with integrated fiberoptic and optogenetic technology. J Neural Eng 2007, 4:SI43-56.

41. Bernstein JG, Han X, Henninger MA, Ko EY, Qian X, Franzesi GT, McConnell JP, Stern P, Desimone R, Boyden ES: Prosthetic systems for therapeutic optical activation and silencing of geneticallytargeted neurons. Proc Soc Photo Opt Instrum Eng 2008, 6854:68540H.

42. Schroll C, Riemensperger T, Bucher D, Ehmer J, Voller T, Erbguth K, Gerber B, Hendel T, Nagel G, Buchner E, Fiala A: Light-induced activation of distinct modulatory neurons triggers appetitive or aversive learning in Drosophila larvae. Curr Biol 2006, 16:1741-7.

FI000 Factor 10

Evaluated by Martin Giurfa 22 Sep 2006

43. Adamantidis AR, Zhang F, Aravanis AM, Deisseroth K, de Lecea L: Neural substrates of awakening probed with optogenetic control of hypocretin neurons. Nature 2007, 450:420-4.

FI000 Factor 13

Evaluated by Mark Mayford II Dec 2007, Gary Aston-Jones 14 Apr 2008

44. Huber D, Petreanu L, Ghitani N, Ranade S, Hromadka T, Mainen Z, Svoboda K: Sparse optical microstimulation in barrel cortex drives learned behaviour in freely moving mice. Nature 2008 , $45 I: 6 I-4$.

45. Douglass AD, Kraves S, Deisseroth $K$, Schier AF, Engert F: Escape behavior elicited by single, channelrhodopsin-2-evoked spikes in zebrafish somatosensory neurons. Curr Biol 2008, I8:1 I33-7.

46. Zhang W, Ge W, Wang Z: A toolbox for light control of Drosophila behaviors through Channelrhodopsin 2-mediated photoactivation of targeted neurons. Eur J Neurosci 2007, 26:2405-16.

47. Lagali PS, Balya D, Awatramani GB, Munch TA, Kim DS, Busskamp V, Cepko CL, Roska B: Light-activated channels targeted to ON bipolar cells restore visual function in retinal degeneration. Nat Neurosci 2008, I I:667-75.

FI000 Factor 7

Evaluated by Klaus-Peter Hoffmann 08 May 2008, David Zenisek 20 Jan 2009
48. Farah N, Reutsky I, Shoham S: Patterned optical activation of retinal ganglion cells. ConfProc IEEE Eng Med Biol Soc 2007, I:6368-70.

49. Alilain WJ, Li X, Horn KP, Dhingra R, Dick TE, Herlitze S, Silver J: Light-induced rescue of breathing after spinal cord injury. Neurosci 2008, 28: I 1862-70.

50. Mahoney TR, Luo S, Round EK, Brauner M, Gottschalk A, Thomas JH, Nonet ML: Intestinal signaling to GABAergic neurons regulates a rhythmic behavior in Caenorhabditis elegans. Proc Natl Acad Sci U S A 2008, 105:16350-5.

5I. Liewald JF, Brauner M, Stephens G], Bouhours M, Schultheis C, Zhen M, Gottschalk A: Optogenetic analysis of synaptic function. Nat Methods 2008, 5:895-902.

52. Petreanu L, Huber D, Sobczyk A, Svoboda K: Channelrhodopsin-2assisted circuit mapping of long-range callosal projections. Nat Neurosci 2007, 10:663-8.

FI000 Factor 8

Evaluated by Michael Andresen 27 Apr 2007

53. Toni N, Laplagne DA, Zhao C, Lombardi G, Ribak CE, Gage FH, Schinder AF: Neurons born in the adult dentate gyrus form functional synapses with target cells. Nat Neurosci 2008, I I:90 I-7.

54. Zhang YP, Oertner TG: Optical induction of synaptic plasticity using a light-sensitive channel. Nat Methods 2007, 4:139-4I.

55. Atasoy D, Aponte Y, Su HH, Sternson SM: A FLEX switch targets Channelrhodopsin-2 to multiple cell types for imaging and long-range circuit mapping. J Neurosci 2008, 28:7025-30.

56. Zhang YP, Holbro N, Oertner TG: Optical induction of plasticity at single synapses reveals input-specific accumulation of alphaCaMKII. Proc Natl Acad Sci U S A 2008, 105: 12039-44.

57. Han X, Qian X, Bernstein JG, Zhou H-h, Franzesi GT, Stern P, Bronson RT, Graybiel AM, Desimone R, Boyden ES: Millisecondtimescale optical control of neural dynamics in the nonhuman primate brain. Neuron 2009, 62:191-8.

FI000 Factor 6

Evaluated by John Reynolds 07 May 2009

58. Han X, Chow BY, Zhou H, Klapoetke N, Chuong A, Rajimehr R, Yang A, Baratta MV, Winkle J, Desimone R, Boyden ES: A high-light sensitivity optical neural silencer: development and application to optogenetic control of nonhuman primate cortex. Front Syst Neurosci 201 I, 5:18.

59. Kuhlman SJ, Huang ZJ: High-resolution labeling and functional manipulation of specific neuron types in mouse brain by Creactivated viral gene expression. PLoS ONE 2008, 3:e2005.

60. Tsai HC, Zhang F, Adamantidis A, Stuber GD, Bonci A, de Lecea L, Deisseroth $\mathrm{K}$ : Phasic firing in dopaminergic neurons is sufficient for behavioral conditioning. Science 2009, 324:1080-4.

FI000 Factor 13

Evaluated by Michael Frank 30 Apr 2009, John Dani 04 Sep 2009

6I. Hagglund M, Borgius L, Dougherty KJ, Kiehn O: Activation of groups of excitatory neurons in the mammalian spinal cord or hindbrain evokes locomotion. Nat Neurosci 2010, 13:246-52.

FI000 Factor 8

Evaluated by Lorne Mendell 14 Apr 2010

62. Katzel D, Zemelman BV, Buetfering C, Wolfel M, Miesenbock G: The columnar and laminar organization of inhibitory connections to neocortical excitatory cells. Nat Neurosci 20II, I4:100-7.

FI000 Factor 12

Evaluated by Alain Destexhe II Jan 20II, Kevan A Martin I4 Feb 2011, Rainer Spanagel 25 Feb 2011

63. Synthetic Neurobiology Group home page. [http://syntheticneurobiology.org] 
64. Nagel G, Ollig D, Fuhrmann M, Kateriya S, Musti AM, Bamberg E, Hegemann P: Channelrhodopsin-I: a light-gated proton channel in green algae. Science 2002, 296:2395-8.

\section{FI000 Factor 8}

Evaluated by Wolfgang Junge 06 Aug 2002

65. Zhang F, Prigge M, Beyriere F, Tsunoda SP, Mattis J, Yizhar O, Hegemann P, Deisseroth K: Red-shifted optogenetic excitation: a tool for fast neural control derived from Volvox carteri. Nat Neurosci 2008, I I:631-3.

66. Mogi T, Marti T, Khorana HG: Structure-function studies on bacteriorhodopsin. IX. Substitutions of tryptophan residues affect protein-retinal interactions in bacteriorhodopsin. J Biol Chem 1989, 264:14197-201.

67. Lanyi JK: Proton transfers in the bacteriorhodopsin photocycle. Biochim Biophys Acta 2006, I757:1012-8.

68. Essen LO: Halorhodopsin: light-driven ion pumping made simple? Curr Opin Struct Biol 2002, I 2:516-22.

69. Otomo J: Influence exercised by histidine-95 on chloride transport and the photocycle in halorhodopsin. Biochemistry 1996, 35:6684-9.

70. Sato M, Kikukawa T, Araiso T, Okita H, Shimono K, Kamo N, Demura M, Nitta K: Ser-I30 of Natronobacterium pharaonis halorhodopsin is important for the chloride binding. Biophys Chem 2003, I04:209-16.

7I. Sato M, Kikukawa T, Araiso T, Okita H, Shimono K, Kamo N, Demura M, Nitta K: Roles of SerI30 and ThrI26 in chloride binding and photocycle of pharaonis halorhodopsin. J Biochem 2003, I34:|5|-8.

72. Rüdiger $M$, Haupts $U$, Gerwert K, Oesterhelt D: Chemical reconstitution of a chloride pump inactivated by a single point mutation. EMBO J 1995, 14:1599-606.

73. Rüdiger $M$, Oesterhelt $D$ : Specific arginine and threonine residues control anion binding and transport in the lightdriven chloride pump halorhodopsin. EMBO J 1997, 16:3813-2 I.
74. Berndt A, Yizhar O, Gunaydin LA, Hegemann $P$, Deisseroth $K$ : Bi-stable neural state switches. Nat Neurosci 2009, I 2:229-34.

75. Bamann C, Gueta R, Kleinlogel S, Nagel G, Bamberg E: Structural guidance of the photocycle of channelrhodopsin-2 by an interhelical hydrogen bond. Biochemistry 2010, 49:267-78.

76. Gunaydin LA, Yizhar O, Berndt A, Sohal VS, Deisseroth K, Hegemann P: Ultrafast optogenetic control. Nat Neurosci 20I0, 13:387-92.

77. Wang H, Sugiyama Y, Hikima T, Sugano E, Tomita H, Takahashi T, Ishizuka T, Yawo H: Molecular determinants differentiating photocurrent properties of two channelrhodopsins from chlamydomonas. J Biol Chem 2009, 284:5685-96.

78. Kleinlogel S, Feldbauer K, Dempski RE, Fotis H, Wood PG, Bamann C, Bamberg $E$ : Ultra light-sensitive and fast neuronal activation with the $\mathbf{C a}(2+)$-permeable channelrhodopsin CatCh. Nat Neurosci 2011, 14:513-8.

FI000 Factor 6

Evaluated by Bryan Roth 15 Apr 2011

79. Ma D, Zerangue N, Lin YF, Collins A, Yu M, Jan YN, Jan LY: Role of ER export signals in controlling surface potassium channel numbers. Science 200I, 29 I:316-9.

80. Gradinaru V, Zhang F, Ramakrishnan C, Mattis J, Prakash R, Diester I, Goshen I, Thompson KR, Deisseroth K: Molecular and cellular approaches for diversifying and extending optogenetics. Cell 2010, |4I:|54-65.

FI000 Factor 8

Evaluated by Bryan Roth 16 Apr 2010

8I. Gradinaru V, Thompson KR, Deisseroth K: eNpHR: a Natronomonas halorhodopsin enhanced for optogenetic applications. Brain Cell Biol 2008, 36:129-39.

82. Zhao S, Cunha C, Zhang F, Liu Q, Gloss B, Deisseroth K, Augustine G], Feng G: Improved expression of halorhodopsin for light-induced silencing of neuronal activity. Brain Cell Biol 2008, 36: $|4|-54$. 